\title{
On Optimal Dividend Strategies in the Compound Poisson Model
}

\author{
Hans U. Gerber \\ Ecole des hautes études commerciales \\ Université de Lausanne \\ CH-1015 Lausanne, Switzerland \\ E-mail: hgerber@unil.ch \\ Elias S. W. Shiu \\ Department of Statistics and Actuarial Science \\ The University of Iowa \\ Iowa City, Iowa 52242-1409, USA \\ E-mail: eshiu@stat.uiowa.edu
}

\begin{abstract}
The optimal dividend problem goes back to a paper that Bruno De Finetti presented to the International Congress of Actuaries in New York (1957). For a stock company which pays dividends to its shareholders, what is the strategy that maximizes the expectation of the discounted dividends (until possible ruin)? Jeanblanc-Picqué and Shiryaev (1995) and Asmussen and Taksar (1997) solved the problem by modeling the aggregate net income of the company by a Wiener process and imposing the condition of a bounded dividend rate. Here we study the problem with the Wiener process generalized to a compound Poisson process.
\end{abstract}

Keywords: Optimal dividend strategies, threshold strategies, Hamilton-Jacobi-Bellman equation, mixture of exponentials 


\section{Introduction}

The optimal dividend problem goes back to Bruno De Finetti (1957), who presented his paper at the 15th International Congress of Actuaries in New York City. In classical risk theory, the problem is to calculate the probability of ruin; hopefully, ruin does not occur, and thus the surplus grows indefinitely. As this is not realistic, De Finetti suggested that a company would seek to maximize the expectation of the present value of all dividends before possible ruin. He showed that, under the assumption that the surplus of the company is a discrete process with steps of size plus or minus one only, the optimal dividend-payment strategy is a barrier strategy. That is, any surplus above a certain level would be paid as dividends to the shareholders of the company.

In a series of papers, Karl Borch had followed up on these ideas and made them also accessible to economists. Borch's ideas are summarized in Chapter 6 of Seal (1969); also see Borch $(1974 ; 1990)$. A first treatment of the optimal dividend problem in the classical compound Poisson model can be found in Section 6.4 of Bühlmann (1970).

Jeanblanc-Picqué and Shiryaev (1995) and Asmussen and Taksar (1997) modified the problem in that they considered only strategies with a bounded dividend rate. In the Brownian motion model, they showed that the optimal dividend strategy is now a threshold strategy, that is, dividends should be paid out at the maximal admissible rate as soon as the surplus exceeds a certain threshold. Some down-to-earth calculations for this model can be found in Gerber and Shiu (2005). The purpose of this paper is to examine the analogous questions in the compound Poisson model.

The theoretical foundations are laid in Sections 3 and 4 of the paper. It is shown that the maximal value function of the dividends can be characterized by the Hamilton- 
Jacobi-Bellman equation. In Sections 5 and 6, the value of a threshold strategy is discussed. Explicit results are obtained in the case of exponential claim amount distributions. In Section 7, results for the Brownian motion model are retrieved as limits. For the case of an exponential claim amount distribution, it is shown that the optimal dividend strategy is a threshold strategy, and the optimal threshold is determined. Conditions are given under which the latter is positive. Section 10 shows how the expected present value of 1 due at the time of ruin, under a threshold strategy, can be calculated. In the Appendices, results of Sections 6 and 10 are generalized to the case where the claim amount distribution is a mixture of exponential distributions.

\section{Problem Formulation}

In the classical model of risk theory, the surplus process $\{\mathrm{U}(\mathrm{t})\}$ of an insurance company is given by

$$
\mathrm{U}(\mathrm{t})=\mathrm{U}(0)+\mathrm{ct}-\mathrm{S}(\mathrm{t}), \quad \mathrm{t} \geq 0 .
$$

The premiums are received continuously at a constant rate $\mathrm{c}$, and the aggregate claims process $\{\mathrm{S}(\mathrm{t})\}$ is a compound Poisson process with claim frequency $\lambda$ and individual claim amount probability density function $\mathrm{p}(\mathrm{y}), \mathrm{y} \geq 0$.

We now enrich the model. We assume that the insurance company is a stock company, and dividends are paid to the shareholders according to some dividend strategy. Let $\mathrm{D}(\mathrm{t})$ denote the aggregate dividends paid between time 0 and time $t$, and $\mathrm{X}(\mathrm{t})$ be the company's surplus, net of dividend payments, at time t. Thus,

$$
\mathrm{X}(\mathrm{t})=\mathrm{U}(\mathrm{t})-\mathrm{D}(\mathrm{t}), \quad \mathrm{t} \geq 0 .
$$

Let 


$$
\mathrm{T}=\inf \{\mathrm{t} \geq 0 \mid \mathrm{X}(\mathrm{t})<0\}
$$

be the time of ruin, and

$$
D=\int_{0}^{T} e^{-\delta t} d D(t)
$$

be the present value of all dividends until ruin, where $\delta>0$ is the force of interest for valuation. The company seeks to maximize the expectation of the random variable $\mathrm{D}$.

We study this optimization problem under the constraint that only dividend strategies with dividend rate bounded by a positive constant $\alpha$ are admissible. We assume $\alpha \in(0, \mathrm{c})$, so that the maximal dividend rate is always less than the premium rate. Thus, the constraint is

$$
\mathrm{dD}(\mathrm{t}) \leq \alpha \mathrm{dt}
$$

with $\alpha<\mathrm{c}$.

\section{The HJB Equation}

Let $\mathrm{V}(\mathrm{x})$ denote the supremum of $\mathrm{E}[\mathrm{D}]$, where the supremum is taken over all admissible dividend strategies, and $\mathrm{x}$ is the company's initial surplus,

$$
\mathrm{x}=\mathrm{X}(0)=\mathrm{U}(0)
$$

The function $\mathrm{V}(\mathrm{x})$ satisfies the so-called Hamilton-Jacobi-Bellman (HJB) functional equation:

$$
\operatorname{Max}_{0 \leq r \leq \alpha}\left\{r+(c-r) V^{\prime}(x)\right\}-(\lambda+\delta) V(x)+\lambda \int_{0}^{x} V(x-y) p(y) d y=0, \quad x \geq 0
$$

Equation (3.2) can be explained by Bellman's dynamic programming principle.

We consider the "small" time interval between 0 and dt, and the following dividend strategy. Suppose that between time 0 and time $\mathrm{dt}$, dividends are paid at rate $\mathrm{r}$, and thereafter, an optimal strategy is applied. By conditioning on whether there is a claim in 
this time interval and on the amount of the claim if it occurs, we see that the expectation of the present value of all dividends until ruin is

$$
r d t+e^{-\delta d t}\left[(1-\lambda d t) V(x+(c-r) d t)+\lambda d t \int_{0}^{x} V(x-y) p(y) d y\right]+o(d t)
$$

which is

$$
\mathrm{V}(\mathrm{x})+\left[\mathrm{r}+(\mathrm{c}-\mathrm{r}) \mathrm{V}^{\prime}(\mathrm{x})-(\lambda+\delta) \mathrm{V}(\mathrm{x})+\lambda \int_{0}^{\mathrm{x}} \mathrm{V}(\mathrm{x}-\mathrm{y}) \mathrm{p}(\mathrm{y}) \mathrm{dy}\right] \mathrm{dt}+\mathrm{o}(\mathrm{dt})
$$

Because $\mathrm{V}(\mathrm{x})$ is the optimal value, it must be equal to the maximum value of expression (3.4), where $r \in[0, \alpha]$. Thus, the maximum of the expression within the brackets in (3.4) must be zero, and hence we obtain the functional equation (3.2). On the left-hand side of (3.2), the expression to be maximized is

$$
\mathrm{r}\left[1-\mathrm{V}^{\prime}(\mathrm{x})\right]
$$

for $r \in[0, \alpha]$. Thus, the optimal dividend rate at time 0 is

$$
\begin{aligned}
& r=0 \text { if } \mathrm{V}^{\prime}(\mathrm{x})>1, \\
& \mathrm{r}=\alpha \text { if } \mathrm{V}^{\prime}(\mathrm{x})<1 .
\end{aligned}
$$

If $\mathrm{V}^{\prime}(\mathrm{x})=1$, the dividend rate $\mathrm{r}$ can be any value between 0 and $\alpha$. Then, at time $\mathrm{t} \in(0, \mathrm{~T})$, the optimal dividend rate is

$$
\begin{gathered}
0 \text { if } \mathrm{V}^{\prime}(\mathrm{X}(\mathrm{t}))>1, \\
\alpha \text { if } \mathrm{V}^{\prime}(\mathrm{X}(\mathrm{t}))<1 .
\end{gathered}
$$

In the next section, we show that a strategy with $E[D]$, as a function of the initial surplus $x$, satisfying the HJB equation (3.2) is indeed an optimal strategy. 


\section{Verification of Optimality}

For some given dividend strategy, let

$$
\mathrm{v}(\mathrm{x})=\mathrm{E}[\mathrm{D}],
$$

a function of the initial surplus x. Suppose that $v(x)$ satisfies the HJB equation (3.2).

Consider any other dividend strategy, with dividend rate $r(t)$ and surplus $\mathrm{X}(\mathrm{t})$ at time $\mathrm{t}$.

We claim that

$$
E\left[\int_{0}^{T} e^{-\delta t} r(t) d t \mid X(0)=x\right] \leq v(x)
$$

From this, it follows that $\mathrm{v}(\mathrm{x})=\mathrm{V}(\mathrm{x})$, and hence the given strategy is optimal.

To show (4.2), we consider the compensated process

$$
\left\{\mathrm{e}^{-\delta \mathrm{t}} \mathrm{v}(\mathrm{X}(\mathrm{t}))-\int_{0}^{\mathrm{t}} \mathrm{e}^{-\delta \tau} \kappa(\tau) \mathrm{d} \tau\right\}
$$

for $0 \leq \mathrm{t} \leq \mathrm{T}$, where

$$
\kappa(\tau)=\lim _{\Delta \tau \rightarrow 0} \frac{1}{\Delta \tau} \mathrm{E}\left[\mathrm{e}^{-\delta \Delta \tau} \mathrm{v}(\mathrm{X}(\tau+\Delta \tau))-\mathrm{v}(\mathrm{X}(\tau)) \mid \mathrm{X}(\tau)\right]
$$

(Note that $\kappa(\tau)$ plays the role of a risk premium rate in the theory of life contingencies.)

Because (4.3) is a martingale, we have

$$
E\left[e^{-\delta(t \wedge T)} v(X(t \wedge T))-\int_{0}^{t \wedge T} e^{-\delta \tau} \kappa(\tau) d \tau \mid X(0)=x\right]=v(x)
$$

which implies

$$
-E\left[\int_{0}^{\mathrm{t} \wedge \mathrm{T}} \mathrm{e}^{-\delta \tau} \kappa(\tau) \mathrm{d} \tau \mid \mathrm{X}(0)=\mathrm{x}\right] \leq \mathrm{v}(\mathrm{x})
$$

By a calculation similar to how we obtained (3.4), we see that the right-hand side of (4.4) is

$$
[c-r(\tau)] v^{\prime}(X(\tau))-(\lambda+\delta) v(X(\tau))+\lambda \int_{0}^{X(\tau)} v(X(\tau)-y) p(y) d y
$$


Because the function $\mathrm{v}(\mathrm{x})$ satisfies the HJB equation (3.2), the sum of $\mathrm{r}(\tau)$ and expression (4.7) must be non-positive, that is,

$$
r(\tau)+\kappa(\tau) \leq 0 .
$$

From this and inequality (4.6) we gather that

$$
E\left[\int_{0}^{t \wedge T} e^{-\delta \tau} r(\tau) d \tau \mid X(0)=x\right] \leq v(x) .
$$

Finally, inequality (4.2) is obtained in the limit $\mathrm{t} \rightarrow \infty$.

\section{Threshold Strategies}

If the solution of (3.2) has the property that $\mathrm{V}^{\prime}(\mathrm{x})>1$ for $\mathrm{x}<\mathrm{b}$ and $\mathrm{V}^{\prime}(\mathrm{x})<1$ for $\mathrm{x}$ $>\mathrm{b}$, for some number $\mathrm{b}$, then the optimal dividend strategy is particularly appealing: Whenever $\mathrm{X}(\mathrm{t})<\mathrm{b}$, no dividends are paid, and whenever $\mathrm{X}(\mathrm{t})>\mathrm{b}$, dividends are paid at the maximal rate $\alpha$. We shall call such a dividend strategy a threshold strategy. Figure 1 illustrates how $X(t)$ and $D(t)$ are obtained from a given sample path of $\{X(t)\}$. Note that the (modified) surplus process $\{\mathrm{X}(\mathrm{t})\}$ undergoes a refraction at the level $\mathrm{b}$. 
Figure 1

\section{Illustration of a Threshold Strategy}
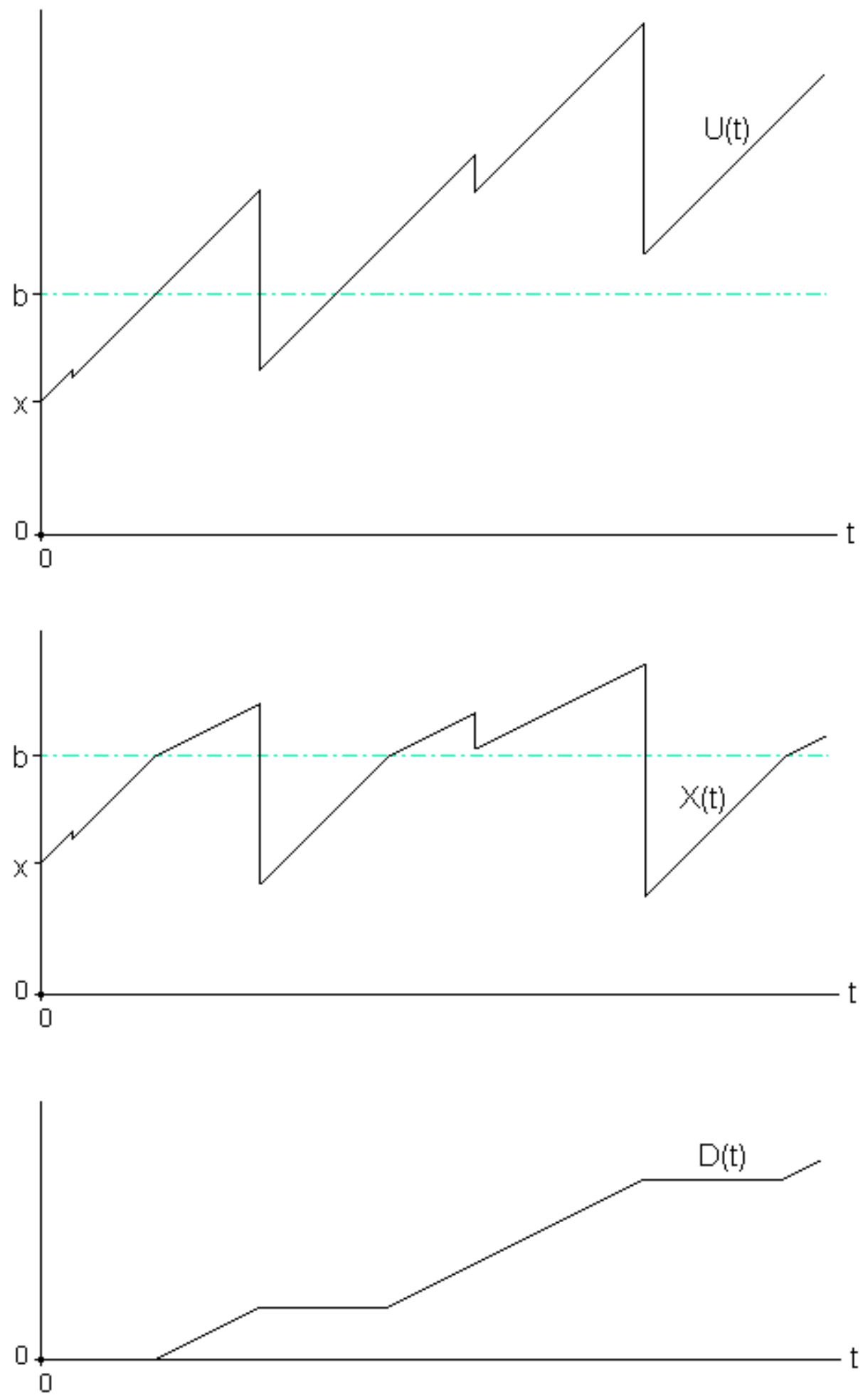
Threshold strategies are of interest, even in cases where the optimal dividend strategy is not of this form. Let $\mathrm{V}(\mathrm{x} ; \mathrm{b})$ denote the expectation of the present value of all dividends until ruin, where $\mathrm{x}$ is the initial surplus and $\mathrm{b}$ is the threshold. As a function of $\mathrm{x}, \mathrm{V}(\mathrm{x} ; \mathrm{b})$ satisfies the following integro-differential equations:

$$
\begin{aligned}
& \mathrm{cV}^{\prime}(\mathrm{x} ; \mathrm{b})-(\lambda+\delta) \mathrm{V}(\mathrm{x} ; \mathrm{b})+\lambda \int_{0}^{\mathrm{x}} \mathrm{V}(\mathrm{x}-\mathrm{y} ; \mathrm{b}) \mathrm{p}(\mathrm{y}) \mathrm{dy}=0, \quad 0<\mathrm{x}<\mathrm{b}, \\
& \alpha+(\mathrm{c}-\alpha) \mathrm{V}^{\prime}(\mathrm{x} ; \mathrm{b})-(\lambda+\delta) \mathrm{V}(\mathrm{x} ; \mathrm{b})+\lambda \int_{0}^{\mathrm{x}} \mathrm{V}(\mathrm{x}-\mathrm{y} ; \mathrm{b}) \mathrm{p}(\mathrm{y}) \mathrm{dy}=0, \quad \mathrm{x}>\mathrm{b}
\end{aligned}
$$

Both equations can be obtained by arguments that are similar to the one used to justify (3.2).

For $\mathrm{x} \rightarrow \infty, \mathrm{V}(\mathrm{x} ; \mathrm{b})$ approaches the present value of a perpetuity with continuous payments at rate $\alpha$,

$$
\lim _{x \rightarrow \infty} V(x ; b)=\frac{\alpha}{\delta}
$$

Finally, one can show that $\mathrm{V}(\mathrm{x} ; \mathrm{b})$ is a continuous function of $\mathrm{x}$ at $\mathrm{x}=\mathrm{b}$. This, together with (5.1)-(5.3), determines the function $\mathrm{V}(\mathrm{x} ; \mathrm{b}), \mathrm{x} \geq 0$. Its derivative, $\mathrm{V}^{\prime}(\mathrm{x} ; \mathrm{b})$, is not necessarily continuous at $\mathrm{x}=\mathrm{b}$. In fact, it follows from (5.1) and (5.2) that

$$
c V^{\prime}(b-; b)=(c-\alpha) V^{\prime}(b+; b)+\alpha .
$$

The integro-differential equation

$$
\operatorname{ch}^{\prime}(x)-(\lambda+\delta) h(x)+\lambda \int_{0}^{x} h(x-y) p(y) d y=0, \quad x>0
$$

has, apart from a constant factor, a unique solution $\mathrm{h}(\mathrm{x})$. It follows from this and (5.1) that

$$
\mathrm{V}(\mathrm{x} ; \mathrm{b})=\gamma \mathrm{h}(\mathrm{x}), \quad 0 \leq \mathrm{x} \leq \mathrm{b}
$$

where $\gamma$ does not depend on $\mathrm{x}$. 
Remark Consider the limiting case $\alpha=\mathrm{c}$, where the threshold becomes a barrier. (See the figure on page 169 of Bühlmann (1970).) Then, condition (5.4) becomes

$$
\mathrm{V}^{\prime}(\mathrm{b}-; \mathrm{b})=1,
$$

and hence (5.6) implies that

$$
\mathrm{V}(\mathrm{x} ; \mathrm{b})=\frac{\mathrm{h}(\mathrm{x})}{\mathrm{h}^{\prime}(\mathrm{b})}, \quad 0 \leq \mathrm{x} \leq \mathrm{b},
$$

which is formula $\left(D_{5}\right)$ on page 172 of Bühlmann (1970).

\section{Exponential Claim Density}

Here we assume that the individual claim amounts are exponentially distributed,

$$
\mathrm{p}(\mathrm{x})=\beta \mathrm{e}^{-\beta \mathrm{x}}, \quad \mathrm{x} \geq 0 .
$$

Then, the integro-differential equation (5.5) can be converted to a linear differential equation with constant coefficients, because

$$
\left(\frac{d}{d x}+\beta\right) \int_{0}^{x} h(x-y) p(y) d y=\beta h(x), \quad x \geq 0 .
$$

To verify (6.2), we observe that the convolution integral in (6.2) can be written as

$$
\int_{0}^{x} h(y) p(x-y) d y
$$

whose derivative with respect to $\mathrm{x}$ is

$$
h(x) p(0)+\int_{0}^{x} h(y) p^{\prime}(x-y) d y=\beta\left[h(x)-\int_{0}^{x} h(y) p(x-y) d y\right] .
$$

Thus, applying the operator $\left(\frac{d}{d x}+\beta\right)$ to equation (5.5) yields the differential equation

$$
\operatorname{ch}^{\prime \prime}(\mathrm{x})+(\beta \mathrm{c}-\lambda-\delta) \mathrm{h}^{\prime}(\mathrm{x})-\beta \delta \mathrm{h}(\mathrm{x})=0 .
$$

The solutions of (6.4) are given by 


$$
h(x)=C_{0} e^{r x}+C_{1} e^{s x}
$$

where $r>0$ and $s<0$ are the roots of the characteristic equation

$$
c \xi^{2}+(\beta c-\lambda-\delta) \xi-\beta \delta=0 .
$$

Substituting (6.5) in (5.5) and equating the coefficient of $\mathrm{e}^{-\beta \mathrm{x}}$ with 0 , we have

$$
\lambda \beta\left(\frac{\mathrm{C}_{0}}{\mathrm{r}+\beta}+\frac{\mathrm{C}_{1}}{\mathrm{~s}+\beta}\right)=0 .
$$

Thus, $h(x)$ is proportional to $(r+\beta) e^{r x}-(s+\beta) e^{s x}$. From this and (5.6), we can write

$$
\mathrm{V}(\mathrm{x} ; \mathrm{b})=\gamma\left[(\mathrm{r}+\beta) \mathrm{e}^{\mathrm{rx}}-(\mathrm{s}+\beta) \mathrm{e}^{\mathrm{sx}}\right], \quad 0 \leq \mathrm{x} \leq \mathrm{b},
$$

where $\gamma$ does not depend on $\mathrm{x}$. In the limiting case $\alpha=\mathrm{c}$, it follows from (5.7) that

$$
\gamma=\frac{1}{(\beta+\mathrm{r}) \mathrm{re}^{\mathrm{rb}}-(\beta+\mathrm{s}) \mathrm{se}^{\mathrm{sb}}},
$$

which agrees with (7.8) in Gerber and Shiu (1998).

$$
\text { Applying the operator }\left(\frac{d}{d x}+\beta\right) \text { to equation (5.2) and rearranging yields the }
$$

differential equation

$$
(c-\alpha) V^{\prime \prime}(x ; b)+[\beta(c-\alpha)-\lambda-\delta] V^{\prime}(x ; b)-\beta \delta V(x ; b)+\beta \alpha=0, \quad x>b,
$$

of which the constant function $\alpha / \delta$ is a particular solution. From this and (5.3), we gather that

$$
\mathrm{V}(\mathrm{x} ; \mathrm{b})=\frac{\alpha}{\delta}+\mathrm{De}^{\mathrm{ux}}, \quad \mathrm{x} \geq \mathrm{b}
$$

where $\mathrm{u}$ is the negative solution of

$$
(c-\alpha) \xi^{2}+[\beta(c-\alpha)-\lambda-\delta] \xi-\beta \delta=0 .
$$

To determine $\gamma$ and D, we need two conditions. From the continuity condition, $\mathrm{V}(\mathrm{b}-; \mathrm{b})=\mathrm{V}(\mathrm{b}+; \mathrm{b})$, we have 


$$
\gamma\left[(\mathrm{r}+\beta) \mathrm{e}^{\mathrm{rb}}-(\mathrm{s}+\beta) \mathrm{e}^{\mathrm{sb}}\right]=\frac{\alpha}{\delta}+D \mathrm{e}^{\mathrm{ub}} .
$$

For a second condition, we observe that the convolution integral in (5.2) is

$$
\begin{aligned}
& \int_{0}^{\mathrm{x}} \mathrm{V}(\mathrm{z} ; \mathrm{b}) \mathrm{p}(\mathrm{x}-\mathrm{z}) \mathrm{dz} \\
& =\gamma \int_{0}^{\mathrm{b}}\left[(\mathrm{r}+\beta) \mathrm{e}^{\mathrm{rz}}-(\mathrm{s}+\beta) \mathrm{e}^{\mathrm{sz}}\right] \mathrm{p}(\mathrm{x}-\mathrm{z}) \mathrm{dz}+\int_{\mathrm{b}}^{\mathrm{x}}\left[\frac{\alpha}{\delta}+\mathrm{De}^{\mathrm{uz}}\right] \mathrm{p}(\mathrm{x}-\mathrm{z}) \mathrm{dz} \\
& =\beta \mathrm{e}^{-\beta \mathrm{x}}\left\{\gamma\left(\mathrm{e}^{(\beta+r) b}-\mathrm{e}^{(\beta+s) b}\right)+\frac{\alpha}{\delta} \frac{1}{\beta}\left(\mathrm{e}^{\beta \mathrm{x}}-\mathrm{e}^{\beta \mathrm{b} b}\right)+\mathrm{D} \frac{1}{\beta+\mathrm{u}}\left[\mathrm{e}^{(\beta+u) \mathrm{x}}-\mathrm{e}^{(\beta+u) b}\right]\right\} .
\end{aligned}
$$

All other terms in (5.2) do not involve the exponential function $\mathrm{e}^{-\beta x}$. By setting the coefficient of $\mathrm{e}^{-\beta \mathrm{x}}$ to 0 , and then canceling the factor $\beta \mathrm{e}^{\beta \mathrm{b}}$, we obtain our second condition:

$$
\gamma\left(\mathrm{e}^{\mathrm{rb}}-\mathrm{e}^{\mathrm{sb}}\right)-\frac{\alpha}{\delta \beta}-\frac{\mathrm{De}}{\beta+\mathrm{ub}}=0 .
$$

It follows from (6.12) and (6.13) that

$$
\gamma=\frac{-u}{\beta} \frac{\alpha}{\delta} \frac{1}{(r-u) e^{r b}-(s-u) e^{s b}} .
$$

Thus,

$$
\mathrm{V}(\mathrm{x} ; \mathrm{b})=\frac{-\mathrm{u}}{\beta} \frac{\alpha}{\delta} \frac{(\beta+\mathrm{r}) \mathrm{e}^{\mathrm{rx}}-(\beta+\mathrm{s}) \mathrm{e}^{\mathrm{sx}}}{(\mathrm{r}-\mathrm{u}) \mathrm{e}^{\mathrm{rb}}-(\mathrm{s}-\mathrm{u}) \mathrm{e}^{\mathrm{sb}}}, \quad 0 \leq \mathrm{x} \leq \mathrm{b} .
$$

Finally,

$$
V(x ; b)=\frac{\alpha}{\delta}\left[1-e^{u(x-b)}\right]+V(b ; b) e^{u(x-b)}, \quad x \geq b .
$$

Observe that

$$
\mathrm{V}(0 ; 0)=\frac{-\mathrm{u}}{\beta} \frac{\alpha}{\delta} .
$$

Because $\mathrm{V}(0 ; 0)$ is less than $\alpha / \delta$, the present value of a perpetuity with payment rate $\alpha$, we must have $0<-\mathrm{u} / \beta<1$. An algebraic verification is as follows. The expression on 
the left-hand side of (6.11) is negative for $\xi=0$ and positive for $\xi=-\beta$. Hence $u$, the negative solution of (6.11), is between $-\beta$ and 0 .

In Appendix $\mathrm{A}$, it is shown how $\mathrm{V}(\mathrm{x} ; \mathrm{b})$ can be calculated when the claim amount density is a mixture of exponential densities.

\section{The Brownian Motion Model}

We consider the model where the difference between premiums and claims is a Brownian motion with constant drift and diffusion parameters, $\mu$ and $\sigma$, respectively. Thus,

$$
\mathrm{U}(\mathrm{t})=\mathrm{U}(0)+\mu \mathrm{t}+\sigma \mathrm{W}(\mathrm{t})
$$

where $\{\mathrm{W}(\mathrm{t})\}$ is a standard Brownian motion (Wiener process). This model can be viewed as the limit of a family of compound Poisson models with exponential claim amount densities, and in this way many formulas in Gerber and Shiu (2005) can be obtained as limiting results.

By equating the drift and the variance per unit time, we obtain the conditions

$$
\mu=\mathrm{c}-\mathrm{E}[\mathrm{S}(1)]=\mathrm{c}-\frac{\lambda}{\beta},
$$

and

$$
\sigma^{2}=\operatorname{Var}[S(1)]=\frac{2 \lambda}{\beta^{2}} .
$$

Then, in the limit $\lambda \rightarrow \infty, \beta \rightarrow \infty, c \rightarrow \infty$, while under constraints (7.2) and (7.3), the Brownian motion model with parameters $\mu$ and $\sigma$ is obtained.

In the limit, the quadratic equation (6.6) for $\mathrm{r}>0$ and $\mathrm{s}<0$ becomes

$$
\frac{\sigma^{2}}{2} \xi^{2}+\mu \xi-\delta=0,
$$


while the quadratic equation (6.11) for $\mathrm{u}<0$ becomes

$$
\frac{\sigma^{2}}{2} \xi^{2}+(\mu-\alpha) \xi-\delta=0 .
$$

From (6.14), we obtain in the limit the formula

$$
\mathrm{V}(\mathrm{x} ; \mathrm{b})=(-\mathrm{u}) \frac{\alpha}{\delta} \frac{\mathrm{e}^{\mathrm{rx}}-\mathrm{e}^{\mathrm{sx}}}{(\mathrm{r}-\mathrm{u}) \mathrm{e}^{\mathrm{rb}}-(\mathrm{s}-\mathrm{u}) \mathrm{e}^{\mathrm{sb}}} \quad \text { for } 0 \leq \mathrm{x} \leq \mathrm{b}, \quad \text { (7.6) }
$$

which is (2.22) in Gerber and Shiu (2005). Formally, formula (6.15) remains valid in the limit.

\section{Optimal Threshold Strategies}

In some situations, the optimal dividend strategy is a threshold strategy. Let $b^{*}$ denote the optimal threshold. Two cases have to be distinguished.

1) If

$$
\mathrm{V}^{\prime}(\mathrm{x} ; 0)<1 \text { for } \mathrm{x}>0
$$

then the threshold strategy with $b^{*}=0$ is optimal.

2) If the optimal strategy is the threshold strategy with $b^{*}>0$, we must have

$$
\begin{aligned}
& V^{\prime}\left(x ; b^{*}\right)>1 \text { for } x<b^{*}, \\
& V^{\prime}\left(x ; b^{*}\right)<1 \text { for } x>b^{*} .
\end{aligned}
$$

Formula (5.4) shows that $\mathrm{V}^{\prime}(\mathrm{b}-; \mathrm{b})$ is a weighted average of $\mathrm{V}^{\prime}(\mathrm{b}+; \mathrm{b})$ and 1 . Hence, the two quantities $\mathrm{V}^{\prime}(\mathrm{b}-; \mathrm{b})$ and $\mathrm{V}^{\prime}(\mathrm{b}+; \mathrm{b})$ are both less than 1 , both greater than 1 , or both equal to 1 . From this fact and (8.2) and (8.3), we gather that

$$
\begin{aligned}
& \mathrm{V}^{\prime}\left(\mathrm{b}^{*-} ; \mathrm{b}^{*}\right)=1, \\
& \mathrm{~V}^{\prime}\left(\mathrm{b}^{*+}+\mathrm{b}^{*}\right)=1 .
\end{aligned}
$$


Thus, the optimal threshold $b^{*}$ can be obtained from either one of these two equivalent equations. By writing $\gamma$ in $(5.6)$ as $\mathrm{V}(\mathrm{b} ; \mathrm{b}) / \mathrm{h}(\mathrm{b})$, we see a third method to obtain $\mathrm{b}^{*}$. It is also the value of $b$ that maximizes

$$
\mathrm{V}(\mathrm{x} ; \mathrm{b})=\mathrm{V}(\mathrm{b} ; \mathrm{b}) \frac{\mathrm{h}(\mathrm{x})}{\mathrm{h}(\mathrm{b})}, \quad 0 \leq \mathrm{x} \leq \mathrm{b} .
$$

Furthermore, we remark that

$$
\mathrm{V}\left(\mathrm{x} ; \mathrm{b}^{*}\right)=\frac{\mathrm{h}(\mathrm{x})}{\mathrm{h}^{\prime}\left(\mathrm{b}^{*}\right)}, \quad 0 \leq \mathrm{x} \leq \mathrm{b}^{*} .
$$

To prove (8.7), we differentiate (5.6) with respect to $x$, and then set $x=b=b^{*}$. Applying (8.4) yields $\gamma=1 / \mathrm{h}^{\prime}\left(\mathrm{b}^{*}\right)$, and thus we have (8.7).

Remark Note the difference between (8.7) and (5.8). Formula (5.8) is the valuation formula for a barrier strategy, i.e., for the limiting case $\alpha=$ c. In contrast to (8.7), formula (5.8) holds for arbitrary values of b.

\section{Optimal Dividend Strategies for Exponential Claims}

In this section, we show that for an exponential claim density, the optimal dividend strategy is indeed a threshold strategy. From (6.15), it follows that

$$
\mathrm{V}^{\prime}(\mathrm{x} ; \mathrm{b})=(-\mathrm{u})\left[\frac{\alpha}{\delta}-\mathrm{V}(\mathrm{b} ; \mathrm{b})\right] \mathrm{e}^{\mathrm{u}(\mathrm{x}-\mathrm{b})}, \quad \mathrm{x}>\mathrm{b} .
$$

Thus, $\mathrm{b}^{*}=0$ if condition (8.1) is satisfied, or

$$
(-\mathrm{u})\left[\frac{\alpha}{\delta}-\mathrm{V}(0 ; 0)\right] \leq 1,
$$

which, by (6.16), is 


$$
(-\mathrm{u}) \frac{\alpha}{\delta}\left[1+\frac{\mathrm{u}}{\beta}\right] \leq 1
$$

Now, suppose that the inequalities in (9.2) and (9.3) are changed from " $\leq$ " to " $>$ ". From (8.5) and (9.1), we get the condition for $b^{*}$ :

$$
(-\mathrm{u})\left[\frac{\alpha}{\delta}-\mathrm{V}(\mathrm{b} ; \mathrm{b})\right]=1
$$

that is, $b^{*}$ is the solution of the equation

$$
\mathrm{V}\left(\mathrm{b}^{*} ; \mathrm{b}^{*}\right)=\frac{\alpha}{\delta}+\frac{1}{\mathrm{u}}
$$

From this and (6.15), it follows that

$$
\mathrm{V}\left(\mathrm{x} ; \mathrm{b}^{*}\right)=\frac{\alpha}{\delta}+\frac{1}{\mathrm{u}} \mathrm{e}^{\mathrm{u}\left(\mathrm{x}-\mathrm{b}^{*}\right)}, \quad \mathrm{x} \geq \mathrm{b}^{*}
$$

It remains to verify that conditions (8.2) and (8.3) are satisfied. For condition (8.3), this is easy, because it follows from (9.6) that

$$
\mathrm{V}^{\prime}\left(\mathrm{x} ; \mathrm{b}^{*}\right)=\mathrm{e}^{\mathrm{u}\left(\mathrm{x}-\mathrm{b}^{*}\right)}<1 \quad \text { for } \mathrm{x}>\mathrm{b}^{*} .
$$

To show that condition (8.2) holds, we show that

$$
\mathrm{V}^{\prime \prime}\left(\mathrm{x} ; \mathrm{b}^{*}\right)<0 \quad \text { for } 0 \leq \mathrm{x}<\mathrm{b}^{*} \text {. }
$$

Note that for $0 \leq \mathrm{x} \leq \mathrm{b}$,

$$
\mathrm{V}^{\prime \prime}(\mathrm{x} ; \mathrm{b})=\gamma \mathrm{h}^{\prime \prime}(\mathrm{x})=\gamma \mathrm{e}^{\mathrm{sx}}\left[\mathrm{r}^{2}(\mathrm{r}+\beta) \mathrm{e}^{(\mathrm{r}-\mathrm{s}) \mathrm{x}}-\mathrm{s}^{2}(\mathrm{~s}+\beta)\right]
$$

For $0 \leq \mathrm{x} \leq \mathrm{b}$, this expression is maximal at $\mathrm{x}=\mathrm{b}$. Thus, (9.8) is equivalent to the condition that

$$
\mathrm{V}^{\prime \prime}\left(\mathrm{b}^{*}-; \mathrm{b}^{*}\right) \leq 0
$$

From (6.4), with $\mathrm{h}(\mathrm{x})$ replaced by $\mathrm{V}(\mathrm{x} ; \mathrm{b})$, we have

$$
c V^{\prime \prime}\left(b^{*}-; b^{*}\right)=\beta \delta V\left(b^{*} ; b^{*}\right)-(\lambda+\delta-\beta c)
$$

and from (6.9) we have 


$$
(c-\alpha) V^{\prime \prime}\left(b^{*}+; b^{*}\right)=\beta \delta V\left(b^{*} ; b^{*}\right)-(\lambda+\delta-\beta c)
$$

Hence, (9.10) is the same as the condition that

$$
\mathrm{V}^{\prime \prime}\left(\mathrm{b}^{*}+; \mathrm{b}^{*}\right) \leq 0
$$

which is certainly true because

$$
\mathrm{V}^{\prime \prime}\left(\mathrm{b}^{*}+; \mathrm{b}^{*}\right)=-\mathrm{u}^{2}\left[\frac{\alpha}{\delta}-\mathrm{V}\left(\mathrm{b}^{*} ; \mathrm{b}^{*}\right)\right]=\mathrm{u}
$$

by (9.5).

Finally, to obtain closed form expressions for the optimal threshold $b^{*}$, we can solve (9.5) or (8.4) for $b^{*}$. Alternatively, we determine the value of $b$ which maximizes (6.14). This leads to

$$
\mathrm{b}^{*}=\frac{1}{\mathrm{r}-\mathrm{s}} \ln \left(\frac{\mathrm{s}^{2}-\mathrm{us}}{\mathrm{r}^{2}-\mathrm{ur}}\right)
$$

Remark It is possible to express condition (9.3) more explicitly in terms of the original parameters of the model. For this purpose we consider first the limiting situation $b^{*}>0$, $b^{*} \rightarrow 0$. From (9.15) we have the condition

$$
s^{2}-u s=r^{2}-u r
$$

or

$$
\mathrm{u}=\mathrm{r}+\mathrm{s},
$$

which is

$$
\mathrm{u}=-\frac{\beta \mathrm{c}-\lambda-\delta}{\mathrm{c}}
$$

by (6.6). An equivalent condition is that

$$
\mathrm{V}\left(\mathrm{b}^{*} ; \mathrm{b}^{*}\right)=\mathrm{V}(0 ; 0)
$$


which, by (9.5) and (6.16), is

$$
\frac{\alpha}{\delta}+\frac{1}{u}=\frac{-u}{\beta} \frac{\alpha}{\delta}
$$

or

$$
\alpha=\delta \frac{\beta}{-u \beta-u^{2}}
$$

Substitution from (9.16) leads to the condition

$$
\alpha=\delta \frac{\beta c^{2}}{(\lambda+\delta)(\beta c-\lambda-\delta)}
$$

The interpretation of this result is as follows. If the denominator is 0 or negative, $b^{*}$ is 0 for any $\alpha$. If the denominator is positive, $b^{*}$ is 0 if $\alpha$ is less than or equal to the expression on the right-hand side of (9.20), and $b^{*}$ is positive if $\alpha$ is greater than this expression. In the limit described in Section 7, formula (9.20) becomes

$$
\alpha=\delta \frac{\sigma^{2}}{2 \mu},
$$

which corresponds to (4.9) and (4.10) in Gerber and Shiu (2005). 


\section{The Time Value of Ruin under a Threshold Strategy}

As in Section 5, we assume that dividends are paid according to a threshold strategy with parameters $\alpha<\mathrm{c}$ and $\mathrm{b}>0$. Let

$$
\mathrm{L}(\mathrm{x} ; \mathrm{b})=\mathrm{E}\left[\mathrm{e}^{-\delta \mathrm{T}} \mid \mathrm{X}(0)=\mathrm{x}\right], \quad \mathrm{x} \geq 0,
$$

denote the expected present of 1 due at the time of ruin. As a function of $\delta$, this quantity is the Laplace transform of the time-of-ruin distribution.

As a function of $\mathrm{x}, \mathrm{L}(\mathrm{x} ; \mathrm{b})$ satisfies the following integro-differential equations:

$c L^{\prime}(x ; b)-(\lambda+\delta) L(x ; b)+\lambda \int_{0}^{x} L(x-y ; b) p(y) d y+\lambda[1-P(x)]=0,0<x<b$

and

$$
(c-\alpha) L^{\prime}(x ; b)-(\lambda+\delta) L(x ; b)+\lambda \int_{0}^{x} L(x-y ; b) p(y) d y+\lambda[1-P(x)]=0, x>b
$$

Furthermore,

$$
\lim _{x \rightarrow \infty} L(x ; b)=0
$$

and $\mathrm{L}(\mathrm{x} ; \mathrm{b})$ is continuous at $\mathrm{x}=\mathrm{b}$. The function $\mathrm{L}(\mathrm{x} ; \mathrm{b})$ is determined by these conditions.

It follows from (5.1) and (5.2) that

$$
c L^{\prime}(b-; b)=(c-\alpha) L^{\prime}(b+; b)
$$

Thus, $\mathrm{L}^{\prime}(\mathrm{x} ; \mathrm{b})$ is not continuous at $\mathrm{x}=\mathrm{b}$. In the limiting case $\alpha=\mathrm{c}$, condition (10.5) becomes

$$
\mathrm{L}^{\prime}(\mathrm{b}-; \mathrm{b})=0 \text {. }
$$


In the remainder of this section, we calculate $\mathrm{L}(\mathrm{x} ; \mathrm{b})$ for the case where $\mathrm{p}(\mathrm{y})$ is

exponential as in Section 6. Applying the operator $\left(\frac{d}{d x}+\beta\right)$ to equation (10.2) and

using (6.2), we see that $\mathrm{L}(\mathrm{x} ; \mathrm{b})$ satisfies the differential equation

$$
c L^{\prime \prime}(x ; b)+(\beta c-\lambda-\delta) L^{\prime}(x ; b)-\beta \delta L(x ; b)=0, \quad 0<x<b .
$$

Thus,

$$
\mathrm{L}(\mathrm{x} ; \mathrm{b})=\mathrm{C}_{0} \mathrm{e}^{\mathrm{rx}}+\mathrm{C}_{1} \mathrm{e}^{\mathrm{sx}}, \quad 0 \leq \mathrm{x} \leq \mathrm{b},
$$

where $r$ and s, as defined in Section 6, are the solutions of the characteristic equation (6.6). Substitution of (10.8) in (10.2) and equating the coefficient of $\mathrm{e}^{-\beta \mathrm{x}}$ with 0 yields a relation between $\mathrm{C}_{0}$ and $\mathrm{C}_{1}$ :

$$
\frac{\beta}{\beta+\mathrm{r}} \mathrm{C}_{0}+\frac{\beta}{\beta+\mathrm{s}} \mathrm{C}_{1}=1
$$

Next, we apply the operator $\left(\frac{d}{d x}+\beta\right)$ to equation (10.3). This yields the

differential equation

$$
(c-\alpha) L^{\prime \prime}(x ; b)+[\beta(c-\alpha)-\lambda-\delta] L^{\prime}(x ; b)-\beta \delta L(x ; b)=0, \quad x>b .
$$

In view of (10.4), we gather that

$$
\mathrm{L}(\mathrm{x} ; \mathrm{b})=\mathrm{De}^{\mathrm{ux}}, \quad \mathrm{x} \geq \mathrm{b},
$$

where $u$ is the negative solution of the characteristic equation (6.11). The continuity of the function $\mathrm{L}(\mathrm{x} ; \mathrm{b})$ at $\mathrm{x}=\mathrm{b}$ yields the condition

$$
\mathrm{C}_{0} \mathrm{e}^{\mathrm{rb}}+\mathrm{C}_{1} \mathrm{e}^{\mathrm{sb}}=\mathrm{De}^{\mathrm{ub}} .
$$

Finally, we substitute (10.8) and (10.11) in (10.3). This leads to the condition

$$
C_{0} \frac{e^{r b}}{\beta+r}+C_{1} \frac{e^{s b}}{\beta+s}=D \frac{e^{u b}}{\beta+u} .
$$


Equations (10.9), (10.12) and (10.13) are three conditions for determining $\mathrm{C}_{0}, \mathrm{C}_{1}$ and D. They can be solved as follows. Multiplying (10.13) by $(\beta+\mathrm{u})$ and subtracting the resulting equation from (10.12), we get

$$
\mathrm{C}_{0} \mathrm{e}^{\mathrm{rb}} \frac{\mathrm{r}-\mathrm{u}}{\beta+\mathrm{r}}+\mathrm{C}_{1} \mathrm{e}^{\mathrm{sb}} \frac{\mathrm{s}-\mathrm{u}}{\beta+\mathrm{s}}=0 .
$$

Solving equations (10.9) and (10.14) simultaneously, we have

$$
\begin{aligned}
& \mathrm{C}_{0}=\frac{\beta+\mathrm{r}}{\beta} \frac{\mathrm{e}^{\mathrm{sb}}(\mathrm{u}-\mathrm{s})}{\mathrm{e}^{\mathrm{rb}}(\mathrm{r}-\mathrm{u})+\mathrm{e}^{\mathrm{sb}}(\mathrm{u}-\mathrm{s})}, \\
& \mathrm{C}_{1}=\frac{\beta+\mathrm{s}}{\beta} \frac{\mathrm{e}^{\mathrm{rb}}(\mathrm{r}-\mathrm{u})}{\mathrm{e}^{\mathrm{rb}}(\mathrm{r}-\mathrm{u})+\mathrm{e}^{\mathrm{sb}}(\mathrm{u}-\mathrm{s})} .
\end{aligned}
$$

Thus, (10.8) becomes

$$
\mathrm{L}(\mathrm{x} ; \mathrm{b})=\frac{1}{\beta} \frac{(\beta+\mathrm{r})(\mathrm{u}-\mathrm{s}) \mathrm{e}^{\mathrm{rx}+\mathrm{sb}}+(\beta+\mathrm{s})(\mathrm{r}-\mathrm{u}) \mathrm{e}^{\mathrm{sx}+\mathrm{rb}}}{(\mathrm{r}-\mathrm{u}) \mathrm{e}^{\mathrm{rb}}+(\mathrm{u}-\mathrm{s}) \mathrm{e}^{\mathrm{sb}}}, \quad 0 \leq \mathrm{x} \leq \mathrm{b} .
$$

In particular,

$$
\mathrm{L}(\mathrm{b} ; \mathrm{b})=\frac{1}{\beta} \frac{(\mathrm{r}-\mathrm{s})(\beta+\mathrm{u})}{(\mathrm{r}-\mathrm{u}) \mathrm{e}^{-\mathrm{sb}}+(\mathrm{u}-\mathrm{s}) \mathrm{e}^{-\mathrm{rb}}} .
$$

With this, we can express $L(x ; b)$ for $x \geq b$ as

$$
\mathrm{L}(\mathrm{x} ; \mathrm{b})=\mathrm{L}(\mathrm{b} ; \mathrm{b}) \mathrm{e}^{\mathrm{u}(\mathrm{x}-\mathrm{b})}, \quad \mathrm{x} \geq \mathrm{b} .
$$

Remarks (1) As explained in Section 7, the Brownian motion model can be obtained as a limit. For $\beta \rightarrow \infty$, (10.17) yields (6.13) in Gerber and Shiu (2005), where r, s and u are now solutions of equations (7.4) and (7.5).

(2) Suppose that $(c-\alpha)>E[S(1)]$, so that the probability of ruin, $\psi(x ; b)$, is less than 1 . We obtain $\psi(\mathrm{x} ; \mathrm{b})$ from $\mathrm{L}(\mathrm{x} ; \mathrm{b})$ as the limit $\delta \rightarrow 0$. Note that in the limit, $\mathrm{r}=0$, and (6.6) and (6.11) become linear equations for $\mathrm{s}$ and $\mathrm{u}$, respectively, yielding 


$$
\begin{aligned}
& \mathrm{s}=-\left(\beta-\frac{\lambda}{\mathrm{c}}\right), \\
& \mathrm{u}=-\left(\beta-\frac{\lambda}{\mathrm{c}-\alpha}\right)
\end{aligned}
$$

With these substitutions, $(10.17)-(10.19)$ lead to closed form expressions for $\psi(x ; b)$. See also Section VII.1 of Asmussen (2000).

(3) Consider the limiting case $\alpha=\mathrm{c}$. Then, we can apply condition (10.6) to (10.8) to write

$$
\mathrm{L}(\mathrm{x} ; \mathrm{b})=\kappa\left(\mathrm{r} \mathrm{e}^{\mathrm{sx}+\mathrm{rb}}-\mathrm{s} \mathrm{e}^{\mathrm{rx}+\mathrm{sb}}\right), \quad 0 \leq \mathrm{x} \leq \mathrm{b},
$$

where the coefficient $\kappa$ can be determined by means of (10.9),

$$
\kappa\left(-\frac{\beta}{\beta+r} \mathrm{se}^{\mathrm{sb}}+\frac{\beta}{\beta+\mathrm{s}} \mathrm{r} \mathrm{e}^{\mathrm{rb}}\right)=1 .
$$

Thus,

$$
\mathrm{L}(\mathrm{x} ; \mathrm{b})=\frac{(\beta+\mathrm{r})(\beta+\mathrm{s})}{\beta} \gamma\left(\mathrm{r} \mathrm{e}^{\mathrm{sx}+\mathrm{rb}}-\mathrm{s} \mathrm{e}^{\mathrm{rx}+\mathrm{sb}}\right), \quad 0 \leq \mathrm{x} \leq \mathrm{b},
$$

with $\gamma$ given by (6.8). This result can be found in Segerdahl (1970, Eq. 18.5), Gerber (1979, p. 150, Eq. 2.4), Lin, Willmot and Drekic (2003, Eq. 6.3), and Dickson and Waters (2004, Eq. 4.4).

(4) Appendix B sketches how L(x; b) can be calculated if $p(y)$ is a mixture of exponential densities. 


\section{Results for $x=b=0$}

Suppose that the threshold strategy with parameter $b=0$ is applied and that the initial surplus is $\mathrm{x}=0$. Then closed form formulas are available for arbitrary claim amount density functions.

From formula (3.9) in Gerber and Shiu (1998), it follows that

$$
\mathrm{L}(0 ; 0)=\mathrm{E}\left[\mathrm{e}^{-\delta \mathrm{T}} \mid \mathrm{X}(0)=\mathrm{b}=0\right]=1-\frac{\delta}{(\mathrm{c}-\alpha) \mathrm{u}_{0}}
$$

where $\mathrm{u}_{0}$ is the positive solution of Lundberg's fundamental equation

$$
(c-\alpha) \xi-(\lambda+\delta)+\lambda \hat{p}(\xi)=0 .
$$

Here, $\hat{\mathrm{p}}(\xi)$ denotes the Laplace transform of the density function $\mathrm{p}(\mathrm{y})$. Hence,

$$
\mathrm{V}(0 ; 0)=\alpha E\left[\frac{1-\mathrm{e}^{-\delta \mathrm{T}}}{\delta} \mid \mathrm{X}(0)=\mathrm{b}=0\right]=\alpha \frac{1-\mathrm{L}(0 ; 0)}{\delta}=\frac{\alpha}{(\mathrm{c}-\alpha) \mathrm{u}_{0}}
$$

In the particular case of an exponential claim amount probability density function $\mathrm{p}$, equation (11.2) boils down to the quadratic equation (6.11). Its solutions are $\mathrm{u}_{0}>0$ and $\mathrm{u}<0$. Then, by observing that

$$
\mathrm{u} \mathrm{u}_{0}=-\frac{\beta \delta}{\mathrm{c}-\alpha}
$$

we can reconcile (6.16) with (11.3).

From (5.2) with $\mathrm{x}=\mathrm{b}=0$ and (11.3), we obtain

$$
\mathrm{V}^{\prime}(0+; 0)=\frac{1}{\mathrm{c}-\alpha}[(\lambda+\delta) \mathrm{V}(0 ; 0)-\alpha]=\frac{\alpha}{\mathrm{c}-\alpha}\left[\frac{\lambda+\delta}{(\mathrm{c}-\alpha) \mathrm{u}_{0}}-1\right]
$$

Hence, $\mathrm{V}^{\prime}(0+; 0) \leq 1$ is equivalent to the condition

$$
\frac{\lambda+\delta}{\mathrm{c}} \leq\left(\frac{\mathrm{c}}{\alpha}-1\right) \mathrm{u}_{0}
$$


Therefore, in cases where the optimal strategy is a threshold strategy, condition (11.6) is equivalent to $b^{*}=0$.

\section{Appendix A}

The purpose of this Appendix is to show how the value of a threshold strategy can be calculated if the individual claim amount density is a mixture of exponential densities,

$$
p(y)=\sum_{i=1}^{n} A_{i} \beta_{i} e^{-\beta_{i} y}, \quad y>0
$$

with $0<\beta_{1}<\beta_{2}<\ldots<\beta_{n}, A_{i}>0$, for $i=1,2, \ldots, n$, and $\sum_{i=1}^{n} A_{i}=1$. The case $n=1$ was treated in Section 6. The Laplace transform of (A1) is

$$
\hat{\mathrm{p}}(\xi)=\sum_{\mathrm{i}=1}^{\mathrm{n}} \mathrm{A}_{\mathrm{i}} \frac{\beta_{\mathrm{i}}}{\beta_{\mathrm{i}}+\xi}
$$

Assume $b>0$; formulas for $b=0$ will be obtained as appropriate limits. If we apply the operator

$$
\prod_{i=1}^{n}\left(\frac{d}{d x}+\beta_{i}\right)
$$

to equation (5.5) and use (6.2), we see that the function $\mathrm{h}(\mathrm{x})$ satisfies a homogeneous differential equation (with constant coefficients) of order $n+1$. Hence, we set

$$
h(x)=\sum_{k=0}^{n} C_{k} e^{\rho_{k} x}
$$

Substitution of (A1) and (A4) in the integro-differential equation (5.5) yields the condition that

$\mathrm{c} \sum_{\mathrm{k}=0}^{\mathrm{n}} \mathrm{C}_{\mathrm{k}} \rho_{\mathrm{k}} \mathrm{e}^{\rho_{\mathrm{k}} \mathrm{x}}-(\lambda+\delta) \sum_{\mathrm{k}=0}^{\mathrm{n}} \mathrm{C}_{\mathrm{k}} \mathrm{e}^{\rho_{\mathrm{k}} \mathrm{x}}+\lambda \sum_{\mathrm{i}=1}^{\mathrm{n}} \sum_{\mathrm{k}=0}^{\mathrm{n}} \mathrm{A}_{\mathrm{i}} \mathrm{C}_{\mathrm{k}} \frac{\beta_{\mathrm{i}}}{\beta_{\mathrm{i}}+\rho_{\mathrm{k}}}\left(\mathrm{e}^{\rho_{\mathrm{k}} \mathrm{x}}-\mathrm{e}^{-\beta_{\mathrm{i}} \mathrm{x}}\right)=0$. (A5) 
Equating the coefficient of $\mathrm{e}^{\rho_{\mathrm{k}} \mathrm{x}}$ with 0 , we obtain the condition that

$$
c \rho_{\mathrm{k}}-(\lambda+\delta)+\lambda \sum_{\mathrm{i}=1}^{\mathrm{n}} \mathrm{A}_{\mathrm{i}} \frac{\beta_{\mathrm{i}}}{\beta_{\mathrm{i}}+\rho_{\mathrm{k}}}=0, \quad \mathrm{k}=0,1, \ldots, \mathrm{n} .
$$

Thus, $\rho_{0}, \rho_{1}, \ldots, \rho_{n}$ are the solutions of

$$
c \xi-(\lambda+\delta)+\lambda \hat{p}(\xi)=0
$$

which is Lundberg's fundamental equation. Analogous of (13.6.15) of Bowers et al. (1997), we have

$$
-\beta_{\mathrm{n}}<\rho_{\mathrm{n}} \ldots<-\beta_{2}<\rho_{2}<-\beta_{1}<\rho_{1}<0<\rho_{0},
$$

showing that $\rho_{0}, \rho_{1}, \ldots, \rho_{\mathrm{n}}$ are distinct numbers.

Also, equating the coefficient of $\mathrm{e}^{-\beta_{\mathrm{i}} \mathrm{x}}$ with 0 , we obtain the condition

$$
\sum_{k=0}^{n} C_{k} \frac{1}{\beta_{i}+\rho_{k}}=0, \quad i=1, \ldots, n .
$$

This is a system of $n$ linear equations for the $(n+1)$ coefficients $C_{0}, C_{1}, \ldots, C_{n}$. Recall that $\mathrm{h}(\mathrm{x})$ is determined only up to a multiplicative constant. In the following, let $\mathrm{C}_{0}, \mathrm{C}_{1}$, $\ldots, C_{n}$ denote a particular solution of (A9).

Now we apply the operator (A3) to equation (5.2) and use the identity (6.2) repeatedly. This way, we see that the function $V(x ; b), x>b$, satisfies a linear differential equation (with constant coefficients) of order $n+1$. A particular solution is, of course, the asymptotic value $\alpha / \delta$. Hence, we set

$$
\mathrm{V}(\mathrm{x} ; \mathrm{b})=\frac{\alpha}{\delta}+\sum_{\mathrm{k}=0}^{\mathrm{n}} \mathrm{D}_{\mathrm{k}} \mathrm{e}^{\mathrm{u}_{\mathrm{k}} \mathrm{x}}, \quad \mathrm{x} \geq \mathrm{b}
$$

We now substitute this expression, (5.6) with $\mathrm{h}(\mathrm{x})$ given by (A4), and (A1) in the integrodifferential equation (5.2). This yields the condition: 


$$
\begin{aligned}
& \alpha+(c-\alpha) \sum_{k=0}^{n} D_{k} u_{k} e^{u_{k} x}-(\lambda+\delta)\left(\frac{\alpha}{\delta}+\sum_{k=0}^{n} D_{k} e^{u_{k} x}\right) \\
& +\gamma \lambda \sum_{i=1}^{n} \sum_{k=0}^{n} A_{i} C_{k} \frac{\beta_{i}}{\beta_{i}+\rho_{k}}\left[e^{\rho_{k} b-\beta_{i}(x-b)}-e^{-\beta_{i} x}\right]+\lambda \frac{\alpha}{\delta} \sum_{i=1}^{n} A_{i}\left[1-e^{-\beta_{i}(x-b)}\right] \\
& +\lambda \sum_{i=1}^{n} \sum_{k=0}^{n} A_{i} D_{k} \frac{\beta_{i}}{\beta_{i}+u_{k}}\left[e^{u_{k} x}-e^{u_{k} b-\beta_{i}(x-b)}\right]=0, \quad x>b .
\end{aligned}
$$

First we note that the constant term on the left-hand side is 0 ; this does not yield a new condition. Now equating the coefficient of $\mathrm{e}^{\mathrm{u}_{\mathrm{k}} \mathrm{x}}$ with 0 , we get the condition that

$$
(c-\alpha) u_{k}-(\lambda+\delta)+\lambda \sum_{i=1}^{n} A_{i} \frac{\beta_{i}}{\beta_{i}+u_{k}}=0, \quad k=0,1, \ldots, n .
$$

This means that $\mathrm{u}_{0}, \mathrm{u}_{1}, \ldots, \mathrm{u}_{\mathrm{n}}$ are the roots of (11.2). Similar to (A8), we have the inequalities

$$
-\beta_{\mathrm{n}}<\mathrm{u}_{\mathrm{n}}<\ldots<-\beta_{2}<\mathrm{u}_{2}<-\beta_{1}<\mathrm{u}_{1}<0<\mathrm{u}_{0} .
$$

It follows from the asymptotic formula (5.3) that $\mathrm{D}_{0}=0$. Finally, we equate the coefficient of $\mathrm{e}^{-\beta_{\mathrm{i}} \mathrm{x}}$ with 0 . This leads to the condition:

$$
\gamma \sum_{k=0}^{n} C_{k} \frac{1}{\beta_{i}+\rho_{k}} e^{\rho_{k} b}-\frac{1}{\beta_{i}} \frac{\alpha}{\delta}-\sum_{k=1}^{n} D_{k} \frac{1}{\beta_{i}+u_{k}} e^{u_{k} b}=0, \quad i=1, \ldots, n .
$$

These are $\mathrm{n}$ linear equations for $\gamma, \mathrm{D}_{1}, \ldots, \mathrm{D}_{\mathrm{n}}$. The remaining condition follows from the continuity of the function $\mathrm{V}(\mathrm{x} ; \mathrm{b})$ at $\mathrm{x}=\mathrm{b}$ :

$$
\mathrm{V}(\mathrm{b}-; \mathrm{b})=\mathrm{V}(\mathrm{b}+; \mathrm{b})
$$

or

$$
\gamma \sum_{\mathrm{k}=0}^{\mathrm{n}} \mathrm{C}_{\mathrm{k}} \mathrm{e}^{\rho_{\mathrm{k}} \mathrm{b}}=\frac{\alpha}{\delta}+\sum_{\mathrm{k}=1}^{\mathrm{n}} \mathrm{D}_{\mathrm{k}} \mathrm{e}^{\mathrm{u}_{\mathrm{k}} \mathrm{b}}
$$


Finally, we consider the case $b=0$. Then

$$
\mathrm{V}(\mathrm{x} ; 0)=\frac{\alpha}{\delta}+\sum_{\mathrm{k}=1}^{\mathrm{n}} \mathrm{D}_{\mathrm{k}} \mathrm{e}^{\mathrm{u}_{\mathrm{k}} \mathrm{x}}, \quad \mathrm{x} \geq 0
$$

The coefficients $D_{1}, \ldots, D_{n}$ are now the solution of a simpler system of linear equations:

$$
\sum_{k=1}^{n} \frac{1}{\beta_{i}+u_{k}} D_{k}=\frac{-\alpha}{\beta_{i} \delta}, \quad i=1, \ldots, n .
$$

To see this, set $b=0$ in (A15) and use (A9). We note that the coefficient matrix of (A18) is a Cauchy matrix (Knuth 1973, p. 36; Pólya and Szegö 1976, p. 279).

Remark The family of combinations of exponential densities (where the $\mathrm{A}_{\mathrm{i}}$ 's in (A1) are not necessarily positive) is much richer than the family of mixtures of exponential densities. If $\mathrm{p}(\mathrm{y})$ is a combination of exponential densities, the value of a threshold strategy can be calculated essentially by the same method, but two points should be kept in mind: Some of the solutions of Lundberg's equations can be complex, and for exceptional constellations of the parameter values, some roots may be multiple roots.

\section{Appendix B}

The purpose of this Appendix is to indicate how $\mathrm{L}(\mathrm{x} ; \mathrm{b})$ can be calculated if $\mathrm{p}(\mathrm{y})$ is a mixture of exponential densities. If we apply the operator (A3) to (10.2), we see that $\mathrm{L}(\mathrm{x} ; \mathrm{b}), 0<\mathrm{x}<\mathrm{b}$, satisfies a homogeneous linear differential equation (with constant coefficients) of order $n+1$. Hence we set

$$
\mathrm{L}(\mathrm{x} ; \mathrm{b})=\sum_{\mathrm{k}=0}^{\mathrm{n}} \mathrm{C}_{\mathrm{k}} \mathrm{e}^{\rho_{\mathrm{k}} \mathrm{x}}, \quad 0 \leq \mathrm{x} \leq \mathrm{b} .
$$

Substitution of (10.2) yields the condition 


$$
\begin{aligned}
& \mathrm{c} \sum_{\mathrm{k}=0}^{\mathrm{n}} \mathrm{C}_{\mathrm{k}} \rho_{\mathrm{k}} \mathrm{e}^{\rho_{\mathrm{k}} \mathrm{x}}-(\lambda+\delta) \sum_{\mathrm{k}=0}^{\mathrm{n}} \mathrm{C}_{\mathrm{k}} \mathrm{e}^{\rho_{\mathrm{k}} \mathrm{x}} \\
& +\lambda \sum_{\mathrm{i}=1}^{\mathrm{n}} \sum_{\mathrm{k}=0}^{\mathrm{n}} \mathrm{A}_{\mathrm{i}} \mathrm{C}_{\mathrm{k}} \frac{\beta_{\mathrm{i}}}{\beta_{\mathrm{i}}+\rho_{\mathrm{k}}}\left(\mathrm{e}^{\rho_{\mathrm{k}} \mathrm{x}}-\mathrm{e}^{-\beta_{\mathrm{i}} \mathrm{x}}\right)+\lambda \sum_{\mathrm{i}=1}^{\mathrm{n}} \mathrm{A}_{\mathrm{i}} \mathrm{e}^{-\beta_{\mathrm{i}} \mathrm{x}}=0 .
\end{aligned}
$$

Equating the coefficient of $\mathrm{e}^{\rho_{\mathrm{k}} \mathrm{x}}$ with 0 , we obtain condition (A6). Thus, $\rho_{0}, \rho_{1}, \ldots, \rho_{\mathrm{n}}$ are defined as in Appendix A, i.e., as the solutions of Lundberg's fundamental equation (A7). Now, equating the coefficient of $\mathrm{e}^{-\beta_{\mathrm{i}} \mathrm{x}}$ with 0 , we obtain the condition

$$
\sum_{k=0}^{\mathrm{n}} \mathrm{C}_{\mathrm{k}} \frac{\beta_{\mathrm{i}}}{\beta_{\mathrm{i}}+\rho_{\mathrm{k}}}=1, \quad \mathrm{i}=1, \ldots, \mathrm{n} .
$$

Applying the operator (A3) to (10.2), we see that $\mathrm{L}(\mathrm{x} ; \mathrm{b}), \mathrm{x}>\mathrm{b}$, satisfies also a homogeneous linear differential equation (with constant coefficients) of order $n+1$. Hence, we set

$$
\mathrm{L}(\mathrm{x} ; \mathrm{b})=\sum_{\mathrm{k}=0}^{\mathrm{n}} \mathrm{D}_{\mathrm{k}} \mathrm{e}^{\mathrm{u}_{\mathrm{k}} \mathrm{x}}, \quad \mathrm{x} \geq \mathrm{b} .
$$

Substitution of (B4) in (10.3) yields the condition

$$
\begin{aligned}
& (c-\alpha) \sum_{k=0}^{n} D_{k} u_{k} e^{u_{k} x}-(\lambda+\delta) \sum_{k=0}^{n} D_{k} e^{u_{k} x}+\lambda \sum_{i=1}^{n} \sum_{k=0}^{n} A_{i} D_{k} \frac{\beta_{i}}{\beta_{i}+u_{k}}\left[e^{u_{k} x}-e^{u_{k} b-\beta_{i}(b-x)}\right] \\
& +\lambda \sum_{i=1}^{n} \sum_{k=0}^{n} A_{i} C_{k} \frac{\beta_{i}}{\beta_{i}+\rho_{k}}\left[e^{\rho_{k} b-\beta_{i}(b-x)}-e^{-\beta_{i} x}\right]+\lambda \sum_{i=1}^{n} A_{i} e^{-\beta_{i} x}=0, \quad x>b .
\end{aligned}
$$

Inspection of the coefficient of $\mathrm{e}^{\mathrm{u}_{\mathrm{k}} \mathrm{x}}$ reveals that $\mathrm{u}_{0}, \mathrm{u}_{1}, \ldots, \mathrm{u}_{\mathrm{n}}$ are the same as those in Appendix A. From (10.4) it follows that $\mathrm{D}_{0}=0$. Note that because of (B3), the coefficient of $\mathrm{e}^{-\beta_{\mathrm{i}} \mathrm{x}}$ on the left-hand side of (B3) vanishes in any case. However, equating the coefficient of $\mathrm{e}^{\beta_{\mathrm{i}} \mathrm{x}}$ with 0 , we obtain the condition 


$$
\sum_{k=1}^{n} D_{k} \frac{\beta_{i}}{\beta_{i}+u_{k}} e^{u_{k} b}=\sum_{k=0}^{n} C_{k} \frac{\beta_{i}}{\beta_{i}+\rho_{k}} e^{\rho_{k} b}, \quad i=1,2, \ldots, n .
$$

Finally, from the continuity of $\mathrm{L}(\mathrm{x} ; \mathrm{b})$ at $\mathrm{x}=\mathrm{b}$, it follows that

$$
\sum_{k=0}^{n} C_{k} e^{\rho_{k} b}=\sum_{k=1}^{n} D_{k} e^{u_{k} b}
$$

In conclusion, (B3), (B6) and (B7) constitute a system of $2 n+1$ linear equations from which the coefficients $\mathrm{C}_{0}, \mathrm{C}_{1}, \ldots, \mathrm{C}_{\mathrm{n}}, \mathrm{D}_{1}, \ldots, \mathrm{D}_{\mathrm{n}}$ can be determined.

\section{Acknowledgment}

We acknowledge with thanks the support from the Patrick Poon Lecture Series Programme in Actuarial Science and the Principal Financial Group Foundation.

\section{References}

Asmussen, Søren. 2000. Ruin Probabilities. Singapore: World Scientific.

Asmussen, Søren, and Michael Taksar. 1997. “Controlled Diffusion Models for Optimal

Dividend Pay-out," Insurance: Mathematics and Economics 20: 1-15.

Borch, Karl. 1974. The Mathematical Theory of Insurance. Lexington, MA: Lexington Books.

Borch, Karl. 1990. Economics of Insurance. Amsterdam: Elsevier.

Bühlmann, Hans. 1970. Mathematical Methods in Risk Theory. Heidelberg: SpringerVerlag.

De Finetti, Bruno. 1957. "Su un' impostazione alternativa dell teoria collettiva del rischio," Transactions of the XVth International Congress of Actuaries 2: 433-443. 
Dickson, David C. M., and Howard Waters. 2004. "Some Optimal Dividends Problems," ASTIN Bulletin 34: 49-74

Gerber, Hans U. 1979. An Introduction to Mathematical Risk Theory. Huebner Foundation Monograph 8, distributed by Richard D. Irwin, Homewood, IL.

Gerber, Hans U., and Elias S. W. Shiu. 1998. “On the Time Value of Ruin,” North American Actuarial Journal, 2 (1): 48-72; Discussions 72-78.

Gerber, Hans U., and Elias S. W. Shiu. 2005. “On Optimal Dividends: From Reflection to Refraction," Journal of Computational and Applied Mathematics, to appear.

Jeanblanc-Picqué, M., and A. N. Shiryaev. 1995. "Optimization of the Flow of Dividends," Russian Mathematical Surveys 20: 257-277.

Knuth, Donald E. 1973. The Art of Computer Programming, Volume 1: Fundamental Algorithms, $2^{\text {nd }}$ ed. Reading, MA: Addison-Wesley.

Pólya, G., Szegö, G., 1976. Problems and Theorems in Analysis, Volume 2. New York: Springer-Verlag.

Segerdahl, C.O. 1970. “On Some Distributions in Time Connected with Collective Risk Theory of Risk.” Scandinavian Actuarial Journal: 167-192.

Seal, H.L. The Stochastic Theory of a Risk Business. New York: Wiley, 1969. 